\title{
Self-Assembly Driven Aggregation-Induced Emission of Silver Nanoclusters for Light Conversion and Temperature Sensing
}

Panpan Sun ${ }^{a}$, Zhi Wang ${ }^{b \ddagger}$,Wenshou Wang ${ }^{\mathrm{a}}$, Yuting Bi ${ }^{\mathrm{b}}$, Di Sun ${ }^{\mathrm{b}}{ }^{*}$,Ting Zhao ${ }^{\mathrm{b}}$, Feifei Zhao ${ }^{\text {a }}$, Xia Xin ${ }^{\text {* }}$

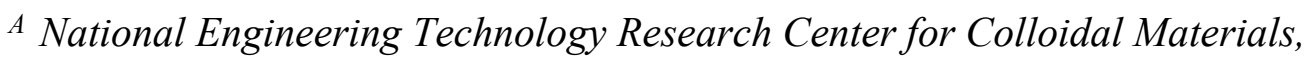
Shandong University, ShandaNanlu No. 27, Jinan, Shandong, 250100, China

${ }^{B}$ Key Laboratory of Colloid and Interface Chemistry, Ministry of Education, School of Chemistry and Chemical Engineering, Shandong University, Jinan, 250100, P. R. China

*Author to whom correspondence should be addressed, E-mail: dsun@sdu.edu.cn Phone: +86-531-88364218. Fax: +86-531-88364216

*Author to whom correspondence should be addressed, E-mail: xinx@sdu.edu.cn Phone: +86-531-88363597. Fax: +86-531-88361008

$\$$ These authors contributed equally to this work. 

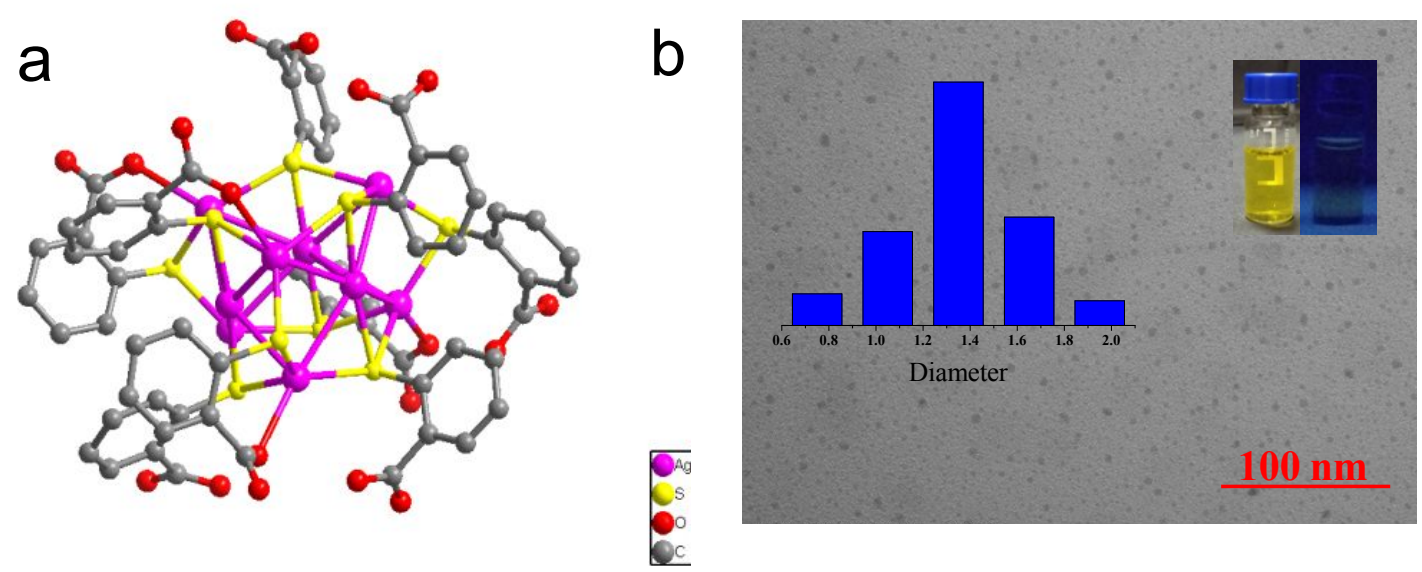

Figure S1 (a) The molecular structure of $\mathrm{Ag}_{9}$-NCs. (b) TEM image of $5 \mathrm{mM}$ $\mathrm{Ag}_{9}-\mathrm{NCs}$ in aqueous solution, In Inset: the results of particle size distribution of $\mathrm{Ag}_{9}-\mathrm{NCs}$ and photographs taken under daylight (left) and $365 \mathrm{~nm}$ UV light (right)
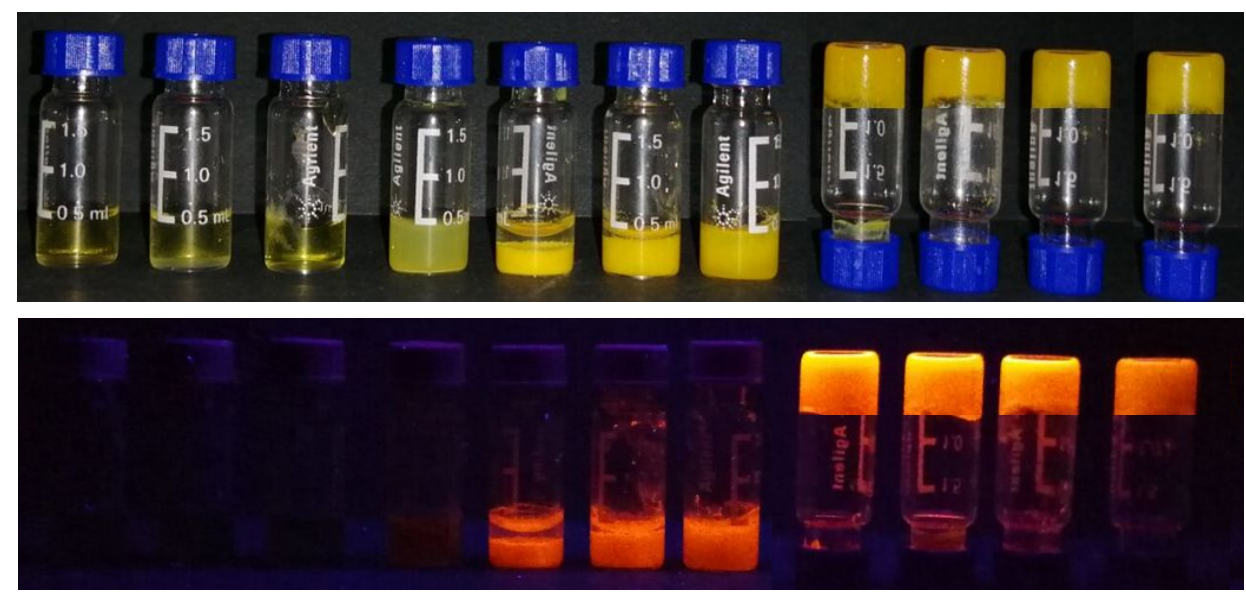

Figure S2 Phase behavior of $\mathrm{Ag}_{9}-\mathrm{NCs}$ at different SA concentrations. (From left to right: 20 mM, 50 mM, 90 mM, 100 mM, 200 mM, 300 mM, 400 mM, 500 mM, 600 $\mathrm{mM}, 700 \mathrm{mM}, 1000 \mathrm{mM})$. 

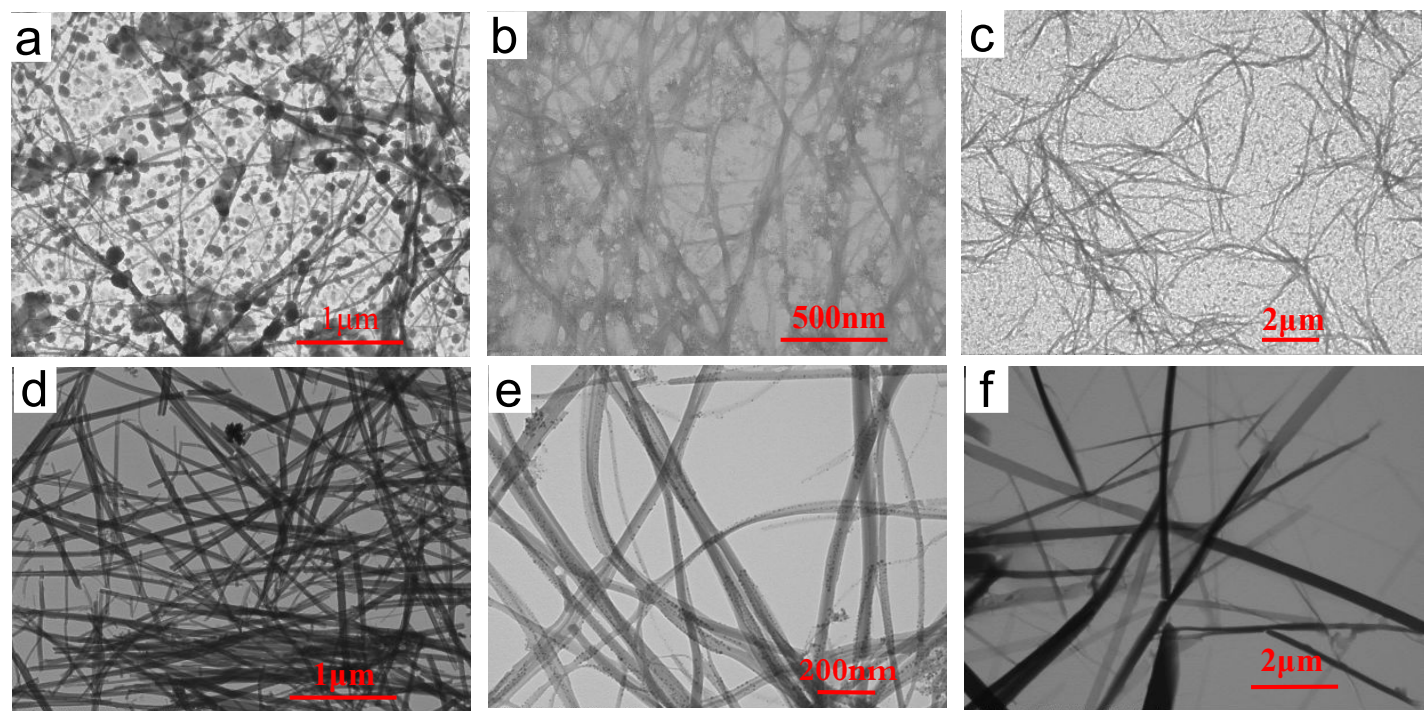

Figure S3 TEM images of different concentrations of SA (a) $5 \mathrm{mM} \mathrm{Ag}_{9}-\mathrm{NCs} / 20 \mathrm{mM}$ $\mathrm{SA}(\mathrm{pH}=3.08)$, (b) $5 \mathrm{mM} \mathrm{Ag}{ }_{9}-\mathrm{NCs} / 50 \mathrm{mM} \mathrm{SA}(\mathrm{pH}=2.77)$, (c) $5 \mathrm{mM} \mathrm{Ag}{ }_{9}-\mathrm{NCs} / 90 \mathrm{mM}$ $\mathrm{SA}(\mathrm{pH}=2.63)$, (d) $5 \mathrm{mM} \mathrm{Ag}{ }_{9}-\mathrm{NCs} / 300 \mathrm{mM} \mathrm{SA}\left(\mathrm{pH}=2.38\right.$ ), (e) $5 \mathrm{mM} \mathrm{Ag}{ }_{9}-\mathrm{NCs} / 500$ mM SA (pH=2.22), (f) $5 \mathrm{mM} \mathrm{Ag}{ }_{9}-\mathrm{NCs} / 700 \mathrm{mM} \mathrm{SA}(\mathrm{pH}=2.17)$.

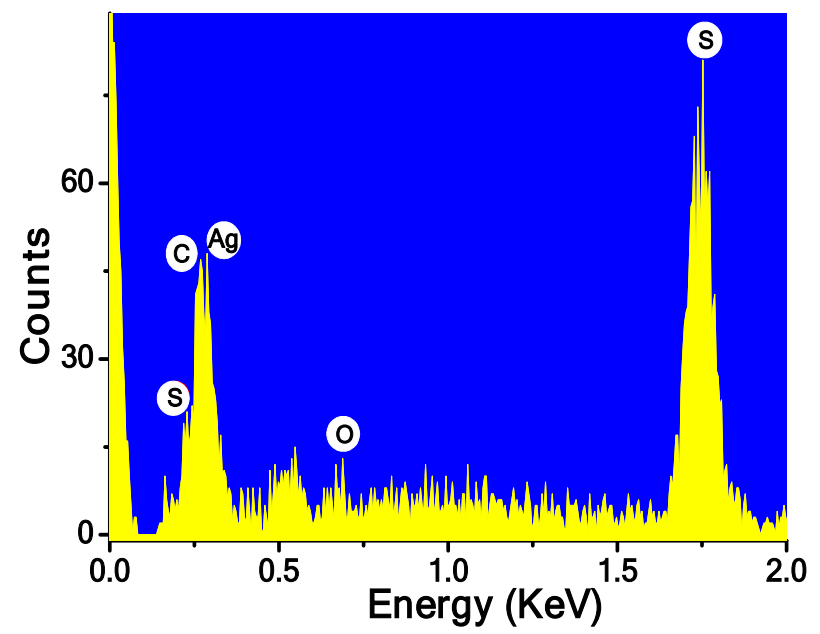

Figure S4 EDX spectrum of the $5 \mathrm{mM} \mathrm{Ag}_{9}-\mathrm{NCs} / 500 \mathrm{mM}$ SA hydrogels
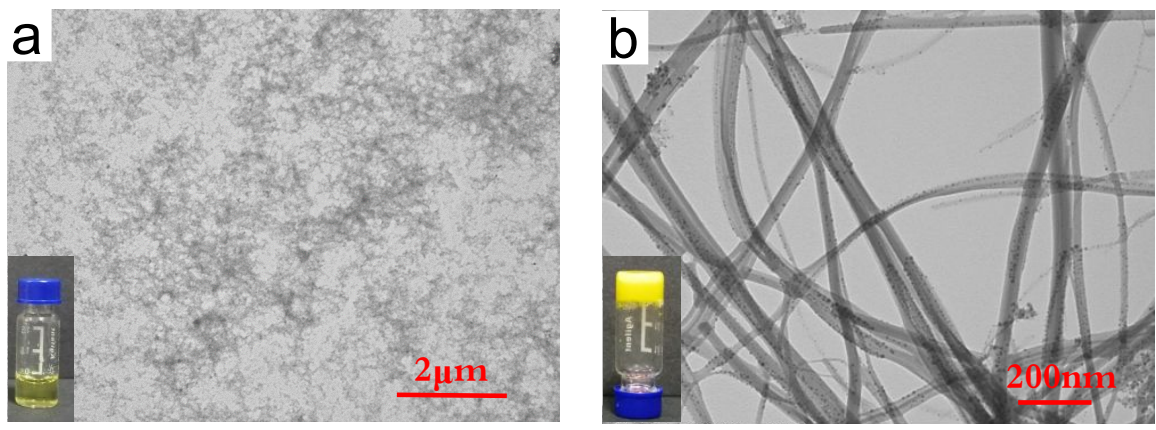
Figure S5 TEM image of (a) $5 \mathrm{mM} \mathrm{Ag}_{9}-\mathrm{NCs} / 500 \mathrm{mM}$ sodium succinate, Inset: photographs taken under daylight. (b) $5 \mathrm{mM} \mathrm{Ag}_{9}-\mathrm{NCs} / 500 \mathrm{mM} \mathrm{SA}$, Inset: photographs taken under daylight.
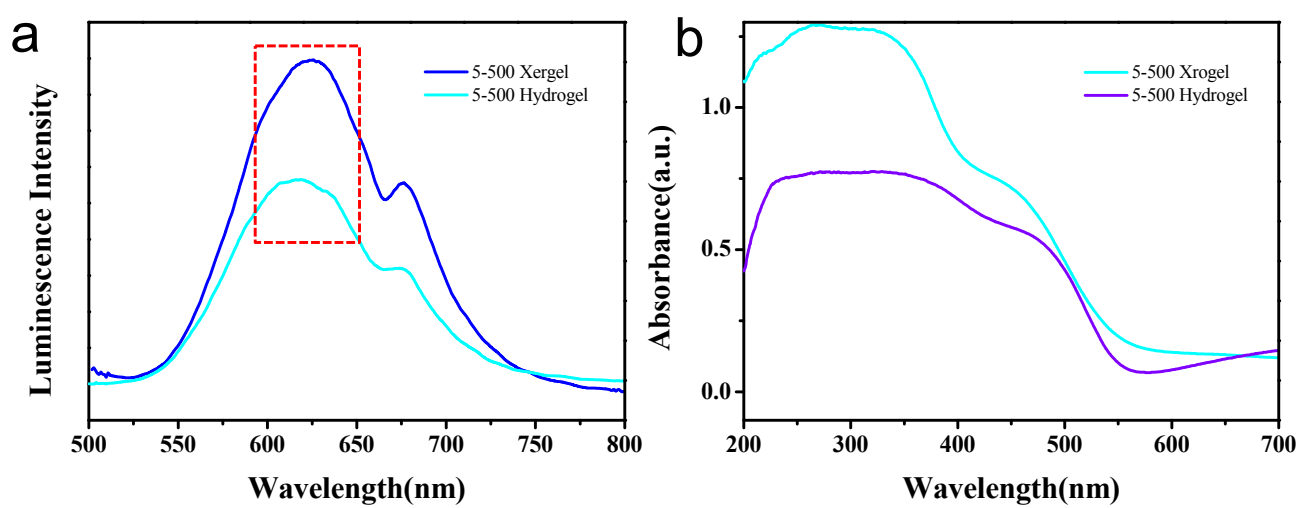

Figure S6 (a) The PL spectra of the $5 \mathrm{mM} \mathrm{Ag}_{9}-\mathrm{NCs} / 500 \mathrm{mM}$ SA hydrogel and the $5 \mathrm{mM} \mathrm{Ag} 9-\mathrm{NCs} / 500 \mathrm{mM}$ SA xerogel. (b) UV-vis absorption spectra of the $5 \mathrm{mM}$ $\mathrm{Ag}_{9}-\mathrm{NCs} / 500 \mathrm{mM}$ SA hydrogels and the $5 \mathrm{mM} \mathrm{Ag}_{9}-\mathrm{NCs} / 500 \mathrm{mM}$ SA xerogels.

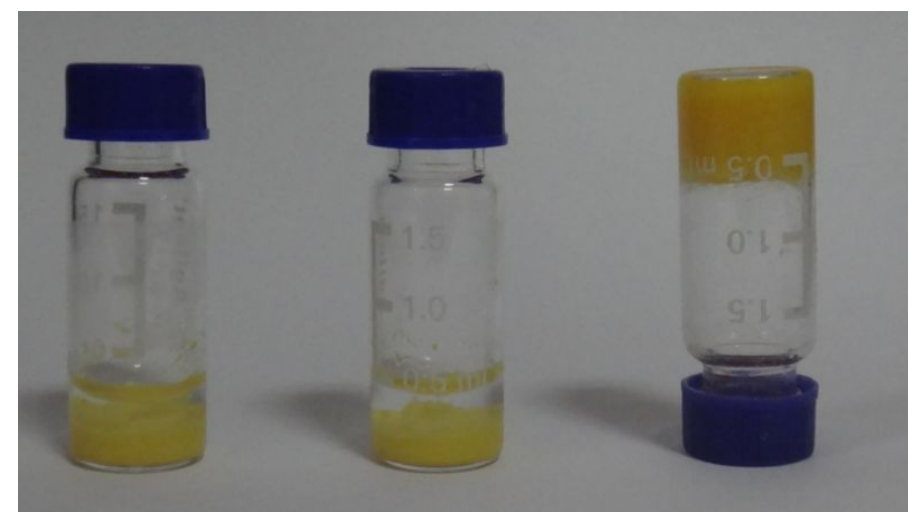

Figure S7 Phase behavior of $5 \mathrm{mM} \mathrm{Ag}_{9}-\mathrm{NCs}$ at different type acid. (From left to right:

$500 \mathrm{mM}$ oxalic acid, $500 \mathrm{mM}$ malonic acid, $500 \mathrm{mM}$ succinic acid).

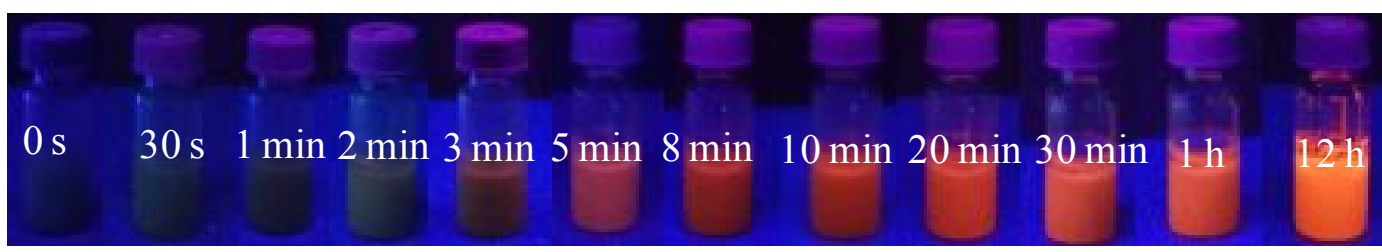


Figure S8 Photographs of the formation process of the hydrogels of $5 \mathrm{mM}$ $\mathrm{Ag}_{9}-\mathrm{NCs} / 500 \mathrm{mM}$ SA irradiated with $365 \mathrm{~nm} \mathrm{UV}$ light.
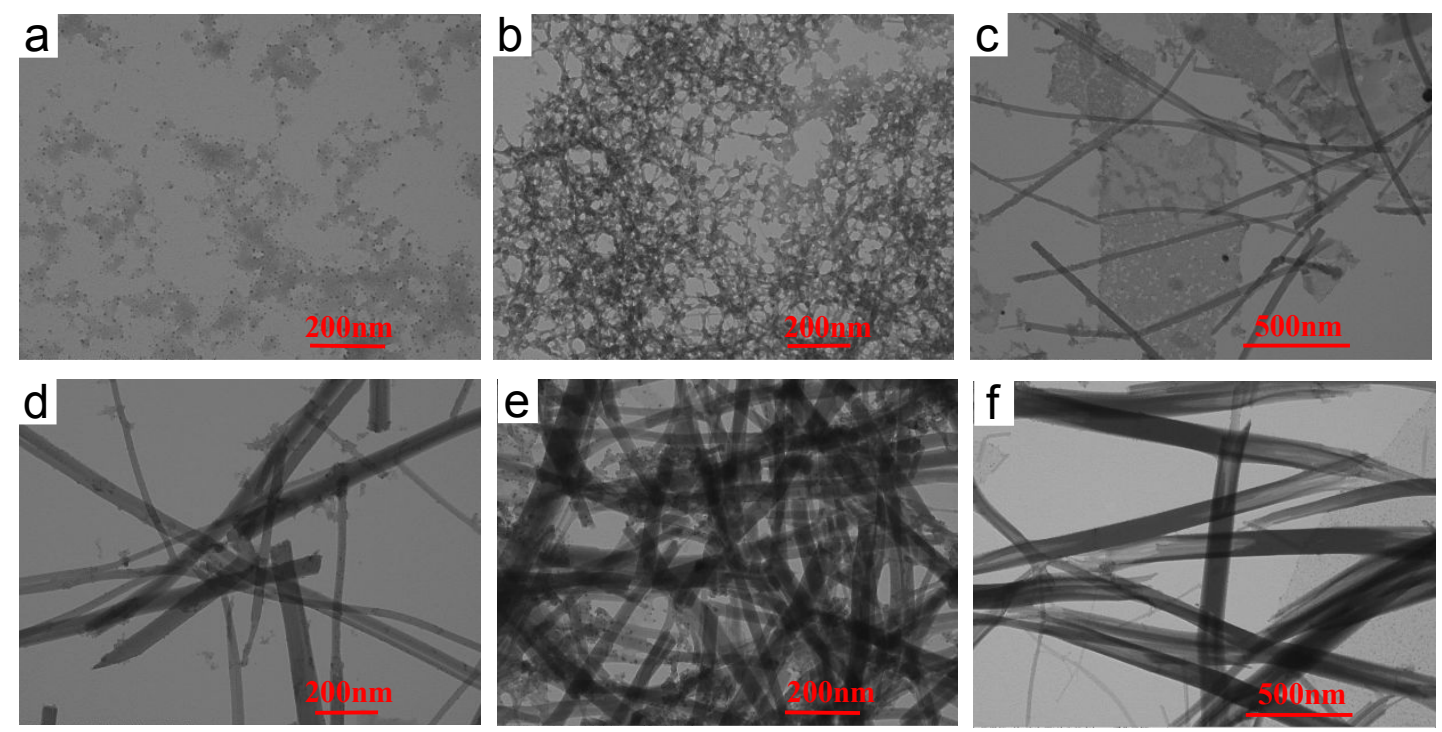

Figure S9 TEM images for the formation process of the hydrogels of $5 \mathrm{mM}$ $\mathrm{Ag}_{9}-\mathrm{NCs} / 500 \mathrm{mM} \mathrm{SA}$ with different incubation time: (a) $0 \mathrm{~s}$, (b) $5 \mathrm{~min}$, (c) $20 \mathrm{~min}$, (d) $1 \mathrm{~h}$, (e) $6 \mathrm{~h}$, (f) $24 \mathrm{~h}$.
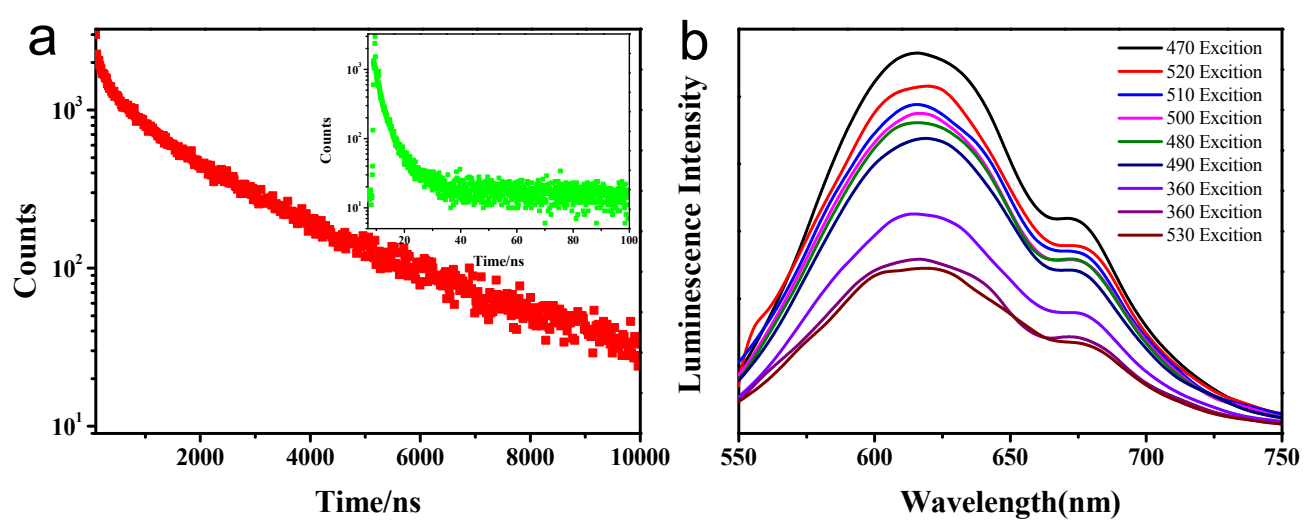

Figure S10 (a) PL decay profiles of $5 \mathrm{mM} \mathrm{Ag}_{9}-\mathrm{NCs} / 500 \mathrm{mM}$ SA hydrogels, inset of

(b) is the PL decay profiles of the powder of lyophilized $\mathrm{Ag}_{9}-\mathrm{NCs}$ solution. (b) Photoemission spectra of $\mathrm{Ag}_{9}-\mathrm{NCs}$ hydrogels under different excitation. 
Table S1 Lifetime of $\mathrm{Ag}_{9}-\mathrm{NCs}$ solution and $5 \mathrm{mM} \mathrm{Ag}{ }_{9}-\mathrm{NCs} / 500 \mathrm{mM}$ SA hydrogels.

\begin{tabular}{ccccc}
\hline Samples/Lifetime & $\tau_{1} / \mathrm{ns}$ & $\tau_{2} / \mathrm{ns}$ & $\tau_{3} / \mathrm{ns}$ & $\tau_{\text {ave }} / \mathrm{ns}$ \\
\hline $\mathrm{Ag}_{9}$-NCs & $0.032(13.1 \%)$ & $1.973(50.7 \%)$ & $6.283(36.2 \%)$ & 3.277 \\
hydrogel & $7.206(1.08 \%)$ & $362.7514(14.12 \%)$ & $2139.2614(84.80 \%)$ & 1865.392 \\
\hline
\end{tabular}

a

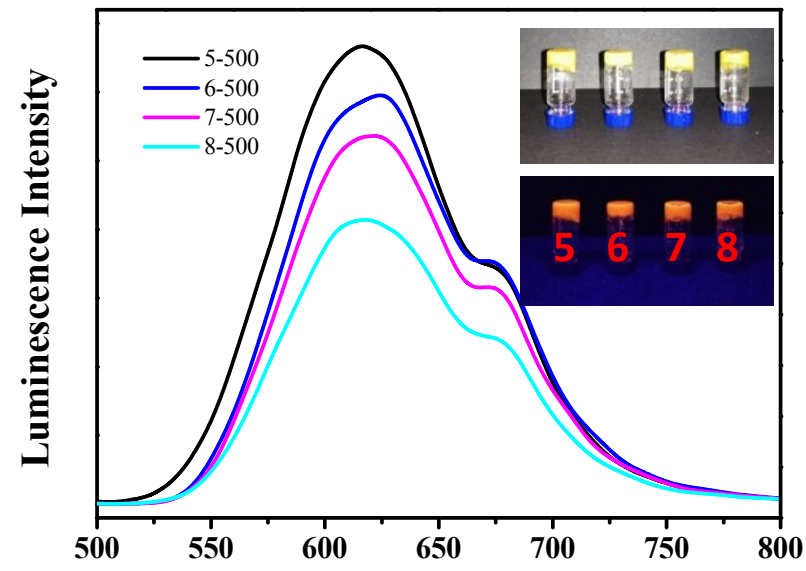

C

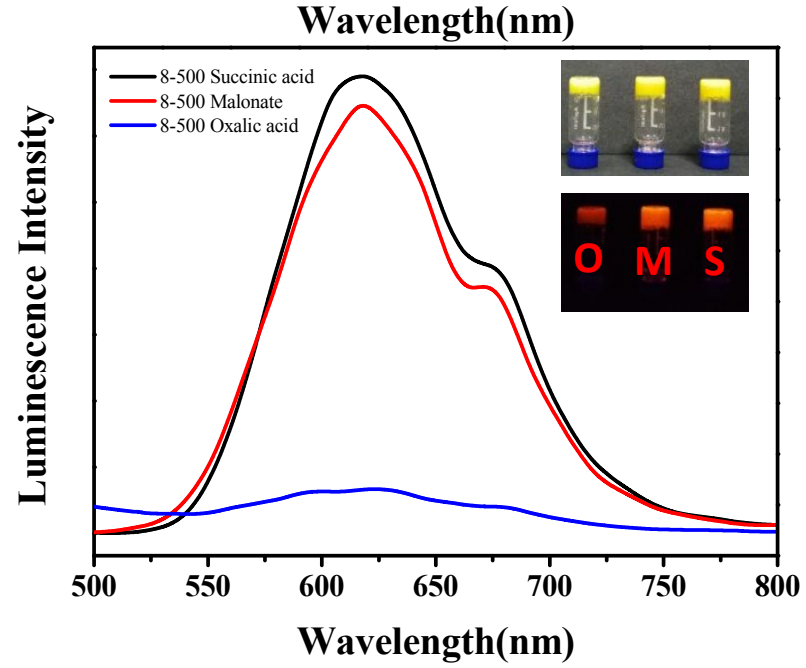

$b$

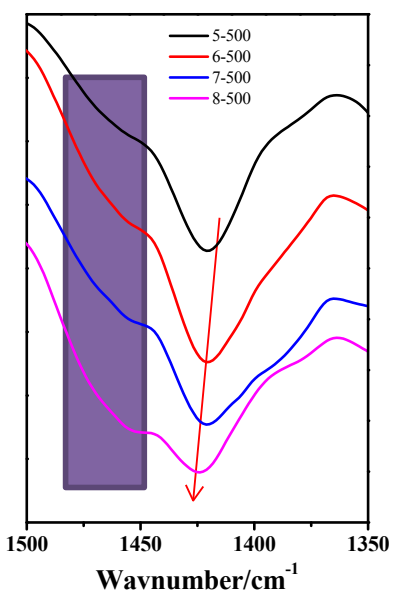

d

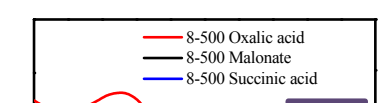

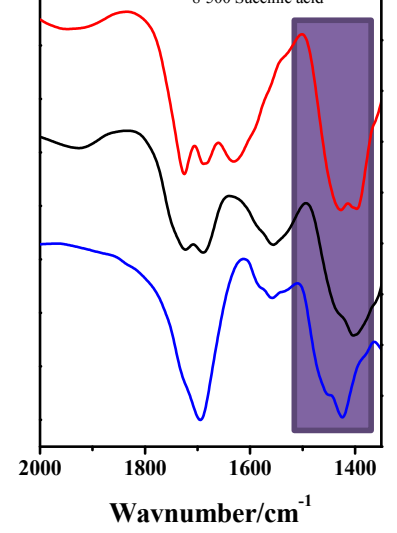

Figure S11 (a) The PL spectra of hydrogels with different concentration $\mathrm{Ag}_{9}-\mathrm{NCs}$ for excitation at $470 \mathrm{~nm}$, the inset shows photographs of $\mathrm{Ag}_{9}-\mathrm{NCs}$ hydrogels under UV light. (b) FT-IR spectra of the powder of the different concentrations of $\mathrm{Ag}_{9}-\mathrm{NCs}$ xerogels. (c) The PL spectra of different types of dibasic acids $\mathrm{Ag}_{9}$-NCs hydrogels. (d) FT-IR spectra of the powder of the different types of dibasic acids $\mathrm{Ag}_{9}{ }^{-\mathrm{NCs}}$ xerogels, the inset shows photographs of different types of dibasic acids $\mathrm{Ag}_{9}$-NCs hydrogels under UV light. 

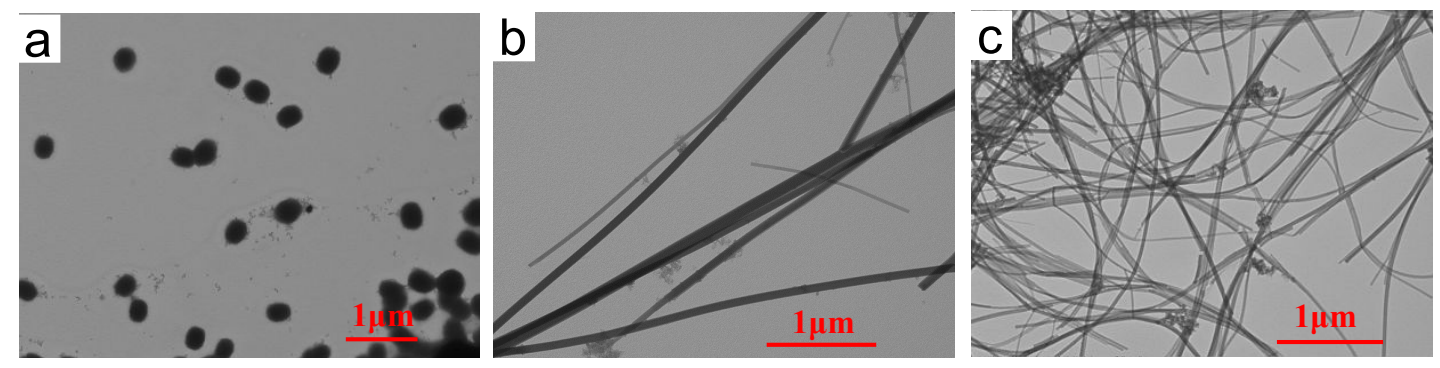

Figure S12 TEM images for the hydrogels of (a) $8 \mathrm{mM} \mathrm{Ag}_{9}-\mathrm{NCs} / 500 \mathrm{mM}$ oxalic acid,

(b) $8 \mathrm{mM} \mathrm{Ag}_{9}-\mathrm{NCs} / 500 \mathrm{mM}$ malonic acid (c) $8 \mathrm{mM} \mathrm{Ag} 9^{-} \mathrm{NCs} / 500 \mathrm{mM}$ succinic acid.

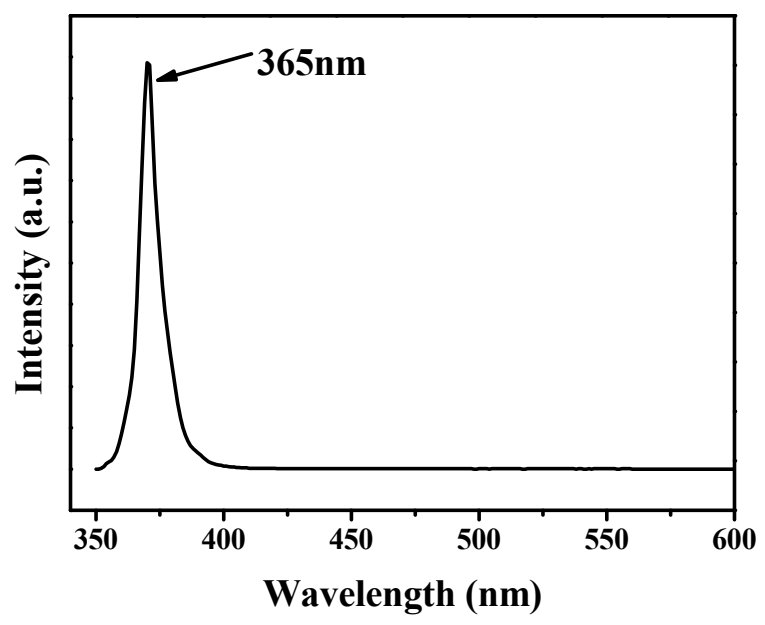

Figure S13 The electro-luminance emission spectrum of LED chip. The emission centers at $365 \mathrm{~nm}$. 